\title{
Uma interpretação do impacto da intranet sobre a vida no trabalho
}

\section{Hermano Roberto Thiry-Cherques}

Pós-Doutorado em Médiation Culturelle, Université de Paris. Doutor em ciência da Engenharia, COPPE - UFRJ. Mestre em Filosofia, IFCS - UFRJ. Bacharel em Administração, EBAP/FGV. Professor Titular - Fundação Getúlio Vargas // Senior Researcher - University of Maryland, College Park.

E-mail: hermano@,fgv.br

\section{Resumo}

Na última década, os sistemas de comunicação conhecidos sob o título de Intranet se estabeleceram como padrão na maioria das organizações. Mesmo as empresas e órgãos governamentais de menor porte fazem uso destes sistemas. Programas para construção de intranets podem ser encontrados com facilidade e adquiridos a preços razoáveis. Neste texto utilizo o instrumental analítico da semiologia estruturalista para interpretar os efeitos da intranet sobre o trabalhador e a vida no trabalho. Aponto evidências de que a intranet, que se apresenta como inclusiva, ampla, livre e participativa, encerra uma estrutura de segregação, cujos elementos determinantes são o assentimento, a subordinação, o estreitamento de perspectivas e a reclusão do trabalhador em um mundo intelectual e emocionalmente restrito.

\section{Palavras-chave}

Intranet. Estruturalismo. Semiologia. Tecnologia da informação. Organizações.

\section{An interpretation of the impact of intranet on the way of living at work}

\begin{abstract}
In the last decade, the systems of communication known as Intranet have been established as a standard in most organizations. Even the smaller government companies and agencies make use of these systems. Programs for building Intranets can be easily found and purchased at a reasonable price. In this text, analytical tools of structuralist semiology were used for interpreting the effects of intranet on the worker and his life at work. Evidently, intranet is presented as inclusive, wide, free and participative, enclosing a segregative structure, the determinant elements of which are acquiescence, subordination, narrowing of perspectives and reclusion of worker in an intellectual and emotionally restricted world.
\end{abstract}

\section{Keywords}

Intranet. Structuralism. Semiology. Information technology. Organizations. 


\section{INTRODUÇÃO}

A revolução desencadeada pelas tecnologias da informação e da comunicação nos anos que antecederam a volta do milênio foi um fenômeno cujas consequências ainda estão por ser avaliadas. A revolução tecnológica provocou uma mudança radical na forma e na intensidade das relações inter e intraorganizacionais. Uma série de práticas administrativas perdeu validade e sentido, diversas foram criadas. Ativos antes cobiçados deixaram de ter valor. Outros foram alçados aos mais altos níveis das prioridades estratégicas. Os padrões e as circunstâncias do trabalho foram completamente alterados. Habilidades e conhecimentos, espaços e relacionamentos caíram em desuso, foram substituídos praticamente da noite para o dia.

Os efeitos desse turbilhão sobre o trabalhador e a vida no trabalho se desdobraram em vários sentidos. Suavizaram a lida diária, livrando-nos dos deslocamentos inúteis, das redundâncias, do esforço improdutivo. Mas também trouxeram novos problemas. Neste artigo, utilizo o instrumental básico da semiologia para analisar as consequências na vida intelectual e emocional do trabalhador da intranet.

A análise a que procedi compreendeu a interpretação do sistema sígnico como expressão da ideologia organizacional e administrativa. O termo "ideologia" é aqui entendido como sistema de ideias sustentadas por um grupo social de qualquer natureza ou dimensão, que racionalizam e defendem interesses e compromissos institucionais, sejam morais, religiosos, políticos ou econômicos. As estruturas subjacentes às intranets, como a todos os sistemas de comunicação não naturais, tendem a fazer prevalecer uma, e só uma, forma de pensar: a forma de pensar daquele que constrói o sistema. Os objetivos declarados da intranet, das empresas, dos governos e de quaisquer instituições em qualquer momento e lugar não são, salvo as exceções de praxe, os verdadeiros objetivos. Isto ocorre sem que os que instituem estes sistemas dêem conta do fato.
Não se trata de uma análise semiológica no sentido estrito desta ciência. Uma análise semiológica se deteria no estudo das relações entre o código do sistema e as mensagens que transmite. Entre os signos e o discurso. Aqui me limitei à aplicação do instrumental semiológico à análise do impacto da intranet sobre a vida no trabalho. Para além das intenções declaradas pelos que instituem os sistemas, detive-me no deciframento do que está disposto na tela do monitor, de um conjunto de imagens utilizadas para transmitir significados buscando desvelar a estrutura subjacente a tal dispositivo.

Procurei entender a intranet como arcabouço virtual das organizações. Utilizei os procedimentos da semiologia estruturalista para identificar os valores e intenções inerentes ao código e aos signos, enquanto identificadores das relações próprias da estrutura codificador-código-decofificador, sobre o qual repousa um sistema do tipo emissor-mensagemreceptor. Empreguei principalmente o instrumental teórico desenvolvido por Barthes (1978), que permite uma utilização profana, não linguística e não tecnológica, na análise de fenômenos como os que interessam às ciências da gestão. Daí a ausência no texto de referências à literatura e ao discurso instituído sobre a funcionalidade das intranets como sistemas comunicacionais e informacionais,

Dividi a apresentação em duas partes. Na primeira, onde procurei resumir os principais conceitos e o instrumental analítico oferecido pela semiologia estruturalista, discuto: a análise semiológica estrutural; os signos e os sintagmas; a intranet como metalinguagem ideográfica do trabalho virtual; o código da intranet como sistema ideográfico. $\mathrm{Na}$ segunda parte, analiso o sistema, a sua representação e expressão, a sua estrutura. Concluo apontando as evidências de que a intranet encerra uma estrutura determinada pelo assentimento, pelo estreitamento, pela subordinação, pela reclusão e pela segregação. 


\section{ELEMENTOS ANALÍTICOS}

\section{Análise semiológica e análise estrutural}

A categoria central da semiologia é o signo, entendido como o agregado formado pelo significante - o veículo que transporta uma expressão ou uma forma - e pelo significado - o conteúdo ou conceito transportado pelo significante. Mais especificamente, a semiologia decompõe o discurso nas seguintes partes:

- referente: o objeto (no caso da intranet, a informação ou dado oferecido ou procurado);

- significado: o conceito que remete ao referente;

- significante: o meio, o suporte, a forma que descreve o conceito. É a forma depositária de um sentido, de uma significação, como, por exemplo, uma palavra ou um som;

- signo: a associação entre o significante e o significado (ECO, 1977; BARTHES, 1978).

- significação: o sentido, o significado que o conceito tem para alguém.

Esses elementos se articulam em um sistema que obedece ao esquema proposto por Barthes (1978), conforme a figura 1.
A análise semiológica opera no campo da investigação dos signos, dos códigos e de sua significação. Engloba tanto as questões relativas à apreensão do sentido dos símbolos, ícones e indícios (palavras, figuras, gestos etc.), quanto da mensagem que eles transmitem. Estuda a constituição dos códigos e as formas como eles são compartilhados. A essência da análise semiológica reside no isolamento dos sistemas de significação e das regras que os governam (BARLEY, 1983).

O elo entre a expressão e o conteúdo, entre o significante e o significado, é uma convenção compartilhada por um grupo (uma cultura). É arbitrário, no sentido de que não há razão alguma que nos leve a chamar uma árvore de /árvore/ em vez de tree, como fazem os ingleses. Isto implica que um mesmo significante pode significar diferentes conteúdos e que o mesmo conteúdo pode ser expresso por diferentes significantes, dependendo das convenções adotadas pelos diversos grupos. Um ícone, como, por exemplo, a figura esquemática de uma casa, indica a existência de um abrigo para um grupo de excursionistas, e indica uma página principal para um usuário da intranet. Um dispositivo de busca, dependendo da convenção, é representado ora por um binóculo, ora por uma lente.

\section{FIGURA 1}

\section{Sistema de significação}

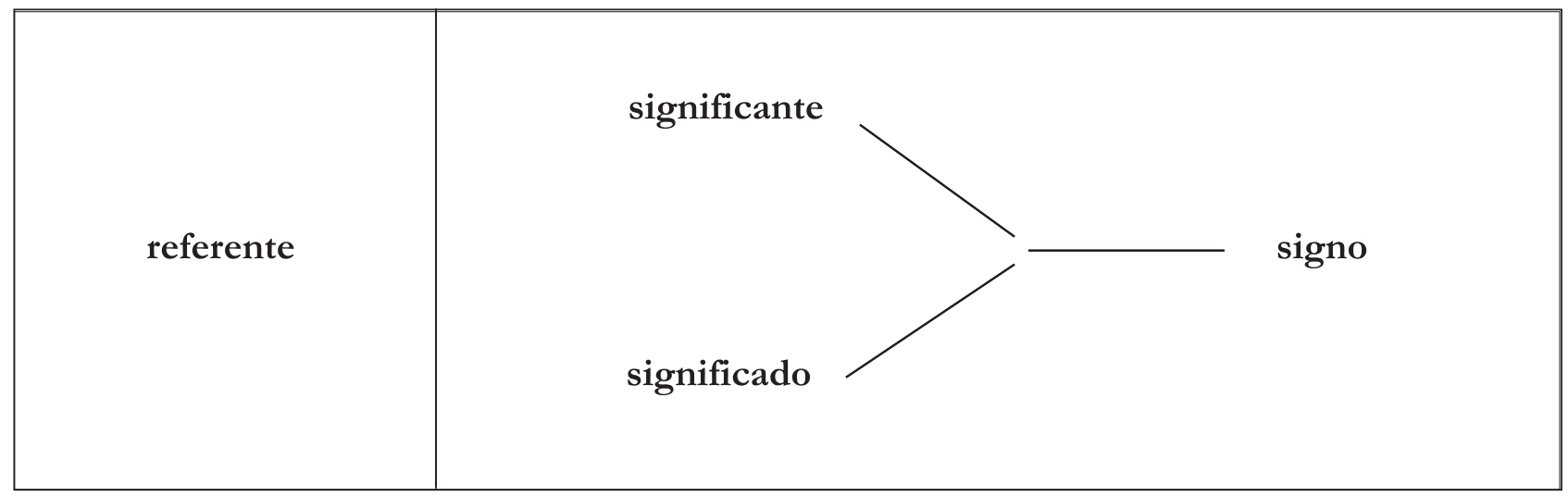

Fonte: Barthes, 2003, p. 184. 
As mensagens que emitimos e recebemos utilizam signos imaginados com vistas a uma significação. A significação, ou o sentido, é o termo final tanto do sistema de imagens como do sistema linguístico. É dada pelo signo de uma linguagem que tomamos de outras linguagens (do português, do inglês, da sinalética consagrada etc.). Conforma uma metalinguagem, como esquematizado na figura 2 (BARTHES, 1978).

O domínio preferencial da linguística e da semiologia é o das linguagens primeiras. Já o campo de estudo da análise que procedo aqui é o da metalinguagem formal como veículo e instrumento de trabalho interno das organizações. A análise da metalinguagem da intranet faz parte, simultaneamente, da semiologia - do estudo das relações entre significantes e significados - e das ciências de gestão: dos estudos que visam a compreender a forma e a dinâmica das organizações.

A parte referida à análise da semiologia compreende os seguintes passos:

- a identificação dos signos;
- a determinação da relação entre o significante e o significado (o que significa o que);

- a identificação do código, isto é, do conjunto articulado de signos;

- a determinação do domínio ao qual o código está confinado, do grupo de pessoas para quem os signos significam da mesma maneira.

A parte referida à análise estrutural utilizando elementos de semiologia compreende o seguinte:

- a identificação das ações (condutas) derivadas da percepção de estímulos e da interpretação dos signos,

- a identificação do sentido do código em determinado domínio, isto é, a estrutura superficial expressa pelo código;

- a interpretação do efeito ou sentido não declarado neste domínio.

Insisto sobre esta distinção porque os estudos semiológicos e semióticos (da abordagem anglosaxã de Peirce (apudECO,1977) têm requerimentos

\section{FIGURA 2}

\section{Linguagem \& metalinguagem}

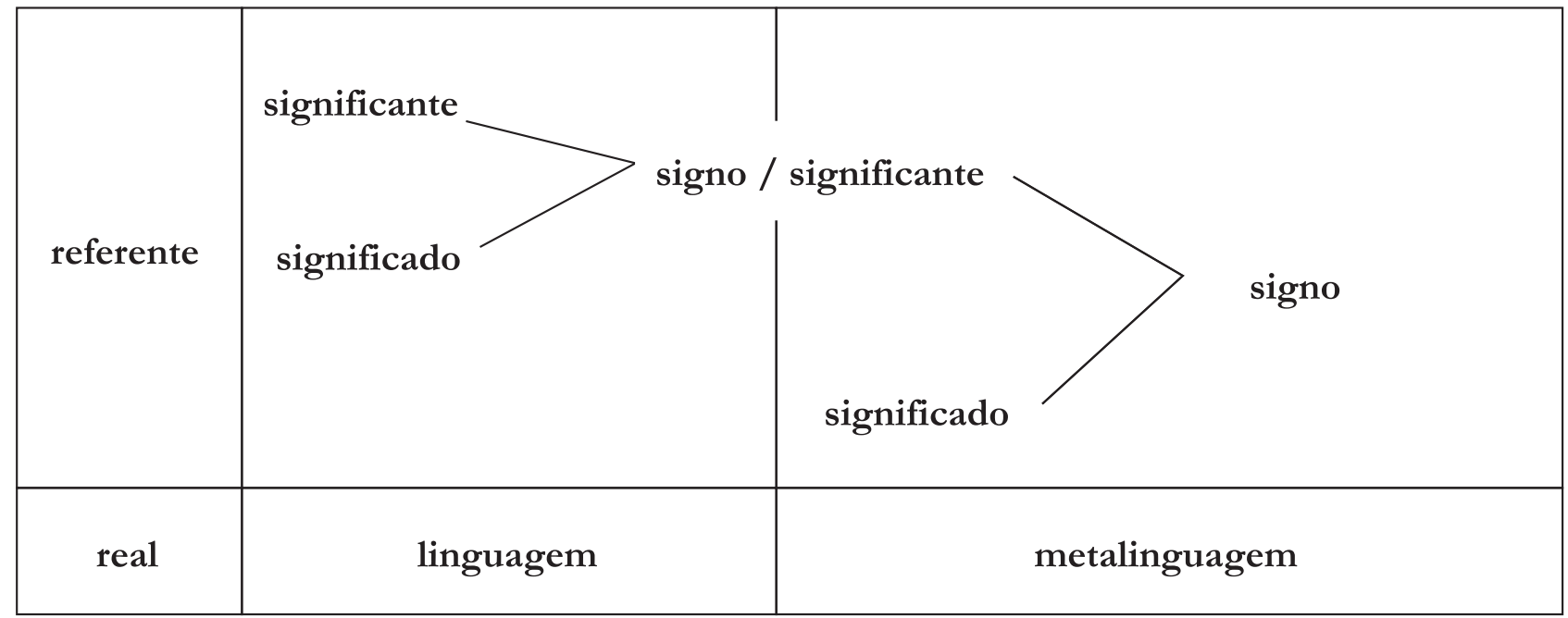

Fonte: Barthes, 1978, p. 138. 
e propósitos diversos dos das ciências da gestão, e ainda para marcar distância dos sistemas de "análise de discurso" e de "análise de conteúdo" que têm contribuído pouco para a compreensão do organizar e do administrar.

O ponto de partida para a análise estrutural de caráter semiológico é a constatação de que os membros de um grupo agem de forma similar à medida que compartilham o mesmo código. Conformam uma cultura organizacional, um conjunto compartilhado de valores, entendimentos e perspectivas. Isto porque, em última instância, é o código que torna o contexto inteligível, que dá sentido ao mundo compartilhado pelo grupo.

A interpretação deste sentido pode se dar estatisticamente ou por saturação. No primeiro caso, opera-se a partir da representatividade da amostragem. No segundo, que é o método que adoto, o entendimento do sentido é considerado completo quando, após várias observações, não é possível acrescentar a ele nenhum elemento. $\mathrm{Na}$ prática, a saturação indica o ponto em que novos temas, categorias ou subcategorias deixam de emergir (MORSE, 1995; GLASER; STRAUSS, 1996; PIRÈS, 1997). Tanto no caso de utilização de instrumental estatístico como no do conceito de saturação, o objetivo da análise estrutural não é generalizar, mas construir um modelo teórico explicativo de determinada realidade.

\section{Os signos e os sintagmas}

O significante e o significado constituem o signo, que pode ser um indício, um símbolo ou um ícone. O indício é imotivado, natural, como a fumaça, por exemplo, é indício de que há fogo, e como qualquer movimento da tela é um indício de que o computador está operando. O símbolo é uma figura considerada como representativa de um referente. A pirâmide é o símbolo do Egito, a pomba é o símbolo da paz. A palavra também é um símbolo e, como todo símbolo, oferece um sentido vago. A figura de uma árvore leva a um conceito concreto (esta árvore), enquanto a palavra /árvore/ é um conceito abstrato (BARTHES, 1978, p. 153). O símbolo e o ícone são produzidos com o fim de significar e são ostensivos. O indício, não. Ele exprime (ou trai) algo que não está deliberadamente expresso.

O significante é uma imagem a decifrar, que pode ser e normalmente é um ícone ou uma palavra-chave (um símbolo). O significado é o conceito resultante da decifração desta imagem. O signo é a totalidade associativa desta imagem e deste conceito.

O signo, portanto, tem uma motivação, algo por trás dele, uma informação cifrada. Existem signos, como a Cruz ou a roda, que são emblemas (símbolos) universais, e existem ícones (na verdade icogramas) produzidos e utilizados dentro de uma linguagem (um código) particular. Os ícones de ferramentas de busca e ampliação, o binóculo e a lente, usuais nas intranet, pertencem ao código da tecnologia da informação. Nós os encontramos por toda a Web, nos editores de texto, em diversos formatos (a lente sobre um papel, por exemplo). Mas eles têm um valor comunicacional relativo. São convencionados, produzidos, ostensivos. Reproduzem algo que remete a uma ideia própria de um domínio; fora dele, têm outro sentido. Podem ter significados diferentes em outros domínios ou o mesmo significado em contexto diverso do da intranet.

A caracterização de um signo como tal depende da existência de um código (ECO, 1977, p. 43). O código nos permite inferir os sentidos para além da comunicação intencional. A inferência é um processo lógico-intelectivo. Vemos uma palavra no alto da tela e inferimos que, dispondo sobre ela o indicador do mouse, uma caixa de opções será aberta. A nossa inferência, construída a partir de um indício, não é intuitiva nem imediata. Pode, inclusive, estar equivocada. A palavra pode não ser um signo da caixa de opções. Ela pode ser um signo autossignificante e não haver caixa alguma. 
A sequência de signos forma um sintagma: um código. Sobre o código se erigem as mensagens. O código não se define pelo seu objeto, mas pela maneira que o profere. Ele pode conter qualquer mensagem, qualquer significação. Tem apenas limites formais: a tela da intranet comunica de determinado modo. Há mensagens quando o código, quando o processo sígnico é reversível. Quando podemos passar do signo ao referente e efetuar também o caminho inverso (PIAGET, 2003, p. 81).

\section{Metalinguagem do trabalho virtual}

O signo é uma imagem à disposição. Por sobre a linguagem real, que reporta o signo ao seu contexto, ele permite criar uma linguagem segunda, uma metalinguagem, referida não às coisas, mas à sua reapresentação, referida não à ação, mas ao gesto (BARTHES, 1978, p. 163). A linguagem do trabalhador se prende à realidade do seu cotidiano. A imagem de uma máquina em um manual de serviço é operatória; a mesma imagem da mesma máquina em um pôster é uma representação. A máquina está no pôster não para ser entendida, mas para ser significada. Ela é um signo, um elemento de outra metalinguagem.

A tela da intranet é um sistema de comunicação, uma linguagem, um modo de significar. Ela denota uma série de significados que permitem navegar pelas várias telas e obter informações. Mas é, também, uma metalinguagem. Em nível mais profundo, ela denota algo que não está imediatamente evidente, que requer uma interpretação. O exemplo dos sinais de trânsito ajuda a compreender esta distinção (figura 3).

Em primeiro nível, temos o signo formado pelo significante /vermelho/ e pelo significado "nãopasse". Em segundo nível, este signo torna-se o significante do significado "obrigação", que, por sua vez, em terceiro nível, é o significante do significado "punição", isto é, do conceito de quem ultrapassa o sinal vermelho será punido. De forma que um simples sinal (signo) de luz integra um código de cores que transporta mensagens.

Muito mais complexas, as imagens que se apresentam na tela da intranet são, simultaneamente, significantes e significados. Enquanto significantes, elas são lidas e interpretadas. Elas têm uma realidade sensorial. Enquanto significados, têm uma realidade psíquica, um valor. Este valor, a significação, postula um saber, o da gestão, que deve ser recuperado. O significante não dá o significado imediatamente. Os discursos que o código intranet veicula têm uma economia interna; devem ser interpretados para que façam sentido.

Para alcançar o conceito encerrado no signo, há de se restabelecer a cadeia de intenções que está por trás do código que se oferece na intranet. Isto só é possível

FIGURA 3

\section{Cadeia de Significação}

\begin{tabular}{|c|c|c|c|c|c|c|c|}
\hline \multirow[t]{3}{*}{ Punição } & \multicolumn{3}{|c|}{$\leftarrow$ Significante de } & \multicolumn{3}{|c|}{ Significante de $\rightarrow$} & decisão \\
\hline & \multirow[t]{2}{*}{ Obrigação } & \multicolumn{2}{|c|}{$\leftarrow$ Significante de } & \multicolumn{2}{|c|}{ Significante de $\rightarrow$} & \multirow[t]{2}{*}{ Escolha } & \\
\hline & & $\begin{array}{l}\text { Significando: } \\
\text { não passe }\end{array}$ & Vermelho & Verde & $\begin{array}{l}\text { Significando: } \\
\text { passe }\end{array}$ & & \\
\hline
\end{tabular}

Fonte: Eco, 1977, p. 116. 
dentro da mesma estrutura, do conjunto sincrônico de significados. Os significantes (as formas) e os significados (os conceitos) e o conjunto articulado de significados (as relações sinaléticas) formam um todo indissolúvel que (de)tem um sentido. Isto é, faz sentido para um grupo que tem um habitus, um modo de ser, que permite ao indivíduo membro do grupo, ao trabalhador imerso no contexto virtual da organização, "ver" nos atributos do signo um fato notável que captura a sua atenção.

\section{O código da intranet é um sistema ideográfico}

$\mathrm{Na}$ cadeia de significação, um significado leva a outro, um signo passa a ser o significante de um passo mais profundo. Vai-se de uma conotação a uma denotação (Figura 4).

Os signos (as palavra, os símbolos) que utilizamos para denotar os elementos das estruturas não representam a experiência do real, mas somente conceitos. Isto é, são o resultado de um esforço de elaboração e, portanto, são condicionados histórica e psicologicamente (PARAIN-VIAL, 1972, p. 77). A metalinguagem denota, representa, mostra mediante signos. O que ela conota, o que ela implica, evoca ou sugere são os sentidos que damos a estes signos. $\mathrm{Na}$ metalinguagem, a atenção se desloca de tal forma que os sujeitos-interpretes se veem ancorados ao habitus construídos por inculcação pedagógica e pela violência simbólica (cf. Bordieu; Passaron; 1982), que dá a consumir somente a imagem, a "ideologia dominante”, expressão que Barthes (2003, p. 60) sustenta ser um pleonasmo.

Os conceitos (significados) transmitidos pela intranet são apropriados à cultura organizacional, ao entendimento dos membros desta cultura. O sentido que transmitem está por trás do signo. A figura do binóculo não é para ser apreendida como o objeto que serve para aproximar a visão do que está longe, mas como um mecanismo de busca de palavras, de informações. É o sentido latente no signo que interessa. $\mathrm{O}$ binóculo poderia ser substituído por um microscópio, ou nem mesmo ser um aparato ótico. A convenção poderia ser um anzol (porque "pescamos" termos). O significado é cultural e pode ser trazido à mente por vários significantes.

Os elementos que constituem a tela da intranet estão ligados entre si por relações associativas. Relações bidimensionais, que remetem a outros signos no plano da tela, e relações tridimensionais,

\section{FIGURA 4}

\section{Denotação \& Conotação}

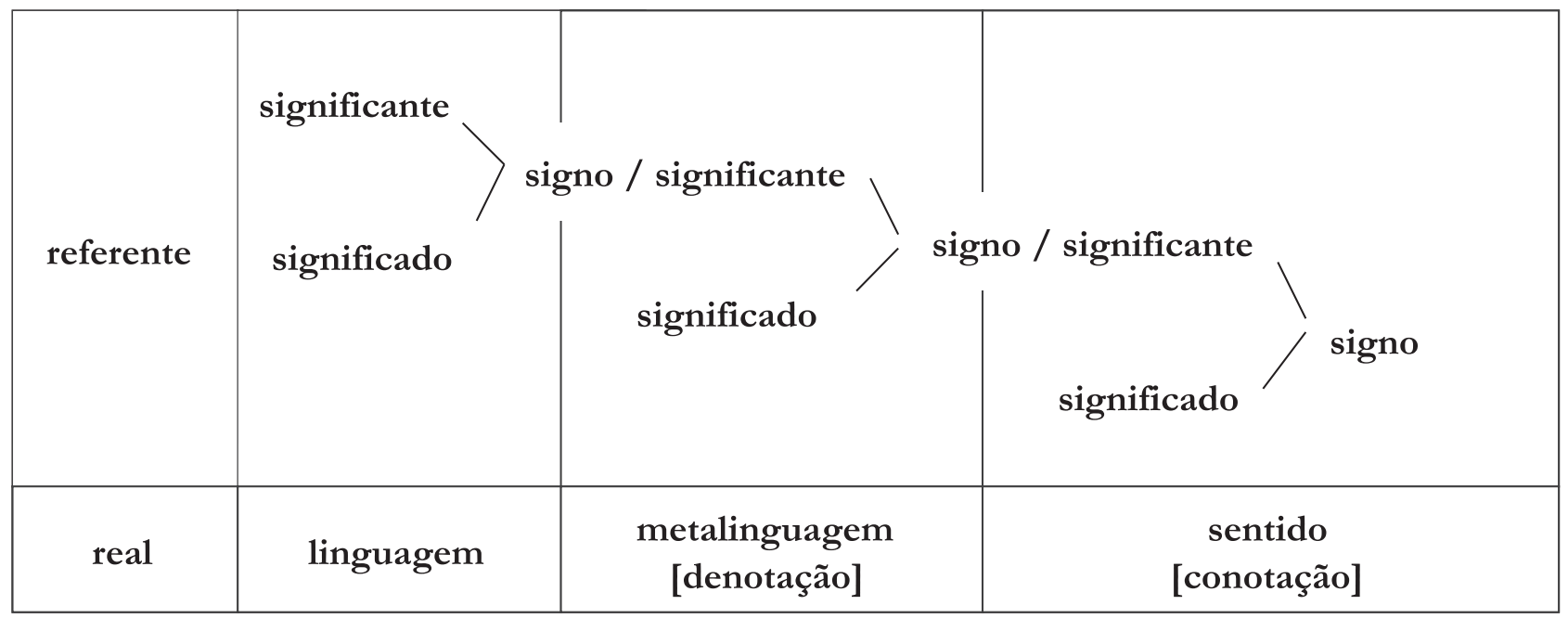

Fonte: elaboração do autor. 
que remetem a signos em outros planos, em outras telas. O/portal/, ou o nome que tenha a tela de entrada, é um meio, uma forma de alcançar os aplicativos disponibilizados (back-office applications). Na tela há uma ordem, uma hierarquia bidimensional da visualização. Ela se apresenta como a forma em que escrevemos no Ocidente: de cima para baixo e da esquerda para a direita. Há cores que se destacam mais ou menos, conforme se distanciam no espectro da cor de fundo. Há figuras e palavras que indicam direções e informações. Esta disposição já evidencia uma orientação do pensamento do usuário. É-lhe transmitida a prioridade da navegação, a hierarquia dos dispositivos de acesso das relações tridimensionais: o hipertexto, a hipermídia que contém a informação ou o serviço desejado. O signo que figura na tela é uma analogia e é um ideograma. As possibilidades da sua leitura dependem de uma interpretação (BARTHES, 1978, p. 149).

\section{Análise da metalinguagem}

A intranet tem uma chave de acesso. Ela é frequentemente o decalque do organograma e reproduz os pontos opacos da organização (JARDIN, 2002, p. 53). Quando olhamos a tela da intranet, o que vemos é um conjunto de significantes, cada um com um significado particular, decifrável para os integrantes da cultura organizacional. A intranet torna transparente uma série de informações que vão das horas trabalhadas ao jornal interno, da localização das pessoas ao menu da cantina. Mas omite e oculta outras.

Para apreendermos o sentido que tem a intranet para o trabalho e o trabalhador, devemos proceder a uma interpretação de segundo nível, devemos interpretar a metalinguagem, o código, os signos enquanto significantes de outros signos e de referentes que constituem a sua estrutura profunda. Da mesma forma que quando olhamos para um lago vemos simultaneamente a superfície de água e o que está para além dela (as pedras do fundo, por exemplo (BACHELARD, 1985, p. 5)), quando olhamos para a tela, vemos signos que ali estão e sabemos, embora não possamos ver, que eles nos remeterão a outros signos, ocultos, mediante os instrumentos da hipermídia. As pedras do fundo do lago nós as vemos retorcidas pela refração. Os caminhos da intranet, simultaneamente revelados e ocultos pelos signos, são distorcidos pelas leis artificiais, ideológicas, abraçadas por quem as construiu.

A interpretação, a elucidação dos significados de uma mídia, é o desvelamento de sentidos ocultos dos signos de significado equívocos (AQUINAS, 1975; S.T.; II, II, ae, q. 120, art. 1 ad 3; RICOEUR, 1965, p. 2;). Nos sistemas semiológicos existem três planos de análise: o do referente, o da linguagem e o do uso do signo (BARTHES, 1971, p. 105). Há muitas formas de interpretar um signo. As mais usuais são as seguintes:

- a alegórica: quando entendemos o signo como tendo um sentido que não é diretamente expresso. O binóculo significa busca: é uma forma aplicada ao conceito;

- a analógica: quando entendemos que a realidade visível, o signo, é a representação de outra realidade. É um conceito que transporta para outro conceito: o binóculo já é a busca;

- a tropológica: quando entendemos que o signo apresenta outra realidade mediante o emprego de uma figura (tropo) que a esconde. Os tropos mais utilizados na análise semiológica são a metonímia, que permite designar qualquer coisa por meio de um outro elemento: (ex. home por tela principal, ou o binóculo pela /busca/, porque o binóculo é um artefato que amplia nossos poderes), e a metáfora, que permite designar uma coisa pela outra em razão da semelhança de significados (ex. a tela em branco, para um questionário não preenchido). Além destas figuras, aparecem na intranet a hipérbole, que exagera uma expressão ("estourar o tempo", por exemplo), e a litotes, o eufemismo, que atenua a expressão para fazer o mais pelo menos (ex. o comando / senha: / por "você não tem direito de acesso a esta informação") (RUSS, 1996, p. 60). 
- a ideológica: quando interpretamos o signo como um tropo filosófico, isto é, como uma figura destinada a provocar uma tensão expressiva intencional. A forma e o conceito imediatos escondem um motivo, uma doutrina sobre o que e sobre o como pode ser buscado. Por exemplo, há uma intenção em se usar o binóculo, a lente, o caderno, a ampulheta: são instrumentos antigos, que remetem a uma época em que a tecnologia servia ao ser humano, e não o contrário, como muitas vezes acontece hoje em dia.

As três primeiras formas de interpretar desvelam a estrutura da metalinguagem. São as formas de análise da semiologia e da psicologia. A última é a forma de interpretar que nos interessa aqui. Ela desvela outra estrutura: a da ideologia, do por que o código e a mensagem da tela são assim e não de outra forma.

\section{Representação e expressão}

A tela do computador emula um processo intelectual e um processo psíquico. Nela existem estímulos sensoriais e estímulos culturais. Como, à diferença da psicolinguística - que se ocupa das possibilidades evocativas e das associações emotivas ligadas a determinado discurso - centrei a análise na expressão das ideias, devo distinguir entre o que é o código e o que é um simples estímulo.

O estímulo sensorial, como, por exemplo, o som que avisa que um procedimento foi completado, é decodificado sem que haja raciocínio. Completase com uma reação (ECO, 1977, p. 27): reagimos ao deslocamento do ponteiro na tela quando movimentamos o mouse, reagimos à barra que pisca, reagimos a vários sons e imagens. $\mathrm{O}$ mesmo acontece com o estímulo cultural, que diz respeito ao conjunto da sociedade e não só à comunidade organizacional. A nossa cultura, por exemplo, valoriza imensamente a imagem. Não porque " uma imagem valha mais do que mil palavras", aforismo que ainda está por ser comprovado, mas porque, desde os gregos, a manualidade é atribuída às atividades subalternas e a ocularidade às superiores. $\mathrm{O}$ trabalhador subalterno manipula, manuseia. $\mathrm{O}$ trabalhador intelectual possui uma visão, lida com evidências, tem ideias (formas visíveis), perspectivas, pontos de vista, enfoques, imaginação (BACHELARD, 1985, p. 12)

Em uma tela intranet, excluídos os estímulos, resta uma variedade imensa de significantes. Alguns deles são simples indícios, outros são símbolos, outros, ainda, ícones. A maioria, no entanto, é significante sem significado, ou significantes que não fazem sentido para o campo do nosso interesse. $\mathrm{Na}$ sentença 'eu vejo a casa', /a/ não tem significado autônomo, mas na sentença 'a $=b^{6}$, /a/ é uma entidade matemática plena de significado. Este é o ponto de vista dos estóicos, que diferenciavam os signos categoremáticos (com significado) dos sincategoremáticos (signos sem significado autônomo, como os artigos, advérbios, que têm seu significado estabelecido pelo contexto). Na sentença 'eu vejo a casa', o / a / é um sincategorema, enquanto /vejo/ e / casa/ são categoremas (ECO, 1977, p. 35). Já o significante/ampulheta/ tem um significado, "em processamento", e uma significação (um sentido); " é preciso esperar", isto é, contém um enunciado que faz determinado sentido em um contexto dado.

Eliminados os estímulos sensoriais e culturais e os significantes sem significado, é possível determinar o domínio da análise. Pensemos no signo / ampulheta/ (escrevo entre barras para indicar que o assumo na sua forma significante). Para quem está familiarizado com a linguagem da TI, /ampulheta/ corresponde a um significado, a um conceito: "procedimento em curso" (escrevo dessa forma para indicar que o assumo como significado). $\mathrm{O}$ significante /ampulheta/ não tem significado para uma cultura diferente da nossa e significa coisas diferentes mesmo em nossa cultura. Para nossos avós, correspondia ao significado "ampulheta" $\mathrm{e}$ poderia ter tanto o sentido de "instrumento para medir o passar do tempo", como o de "que a vida é curta e o tempo passa depressa". 
Para interpretarmos o significado de um significante como /ampulheta/, temos que utilizar outros significantes (verbais, visuais etc.) a que Peirce denominou interpretantes (PEIRCE, apud ECO, 1977, p. 30). Os interpretantes podem ser de três tipos: a) emotivos, as reações sentimentais a um signo; b) energéticos, os atos que o signo faz acontecer, que na nossa perspectiva, funcionam como estímulos; c) expressões lógicas, referidas ao significado (conceito) na mente de quem lê o signo, que são os interpretantes que mais interessam à análise estrutural nas ciências de gestão, enquanto os dois primeiros interessariam mais à psicologia.

No nível da representação, os signos se definem como um conjunto de elementos que não podem ser usados ao mesmo tempo para a mesma função, e cujo acionamento corresponde a uma mudança de foco horizontal (na mesma tela) ou vertical (para outro sítio, seja para outra tela, seja para a informação final procurada ou para fora do sistema). No nível da expressão lógica, eles são verbalizados. Isto porque só a linguagem emitida verbalmente tem um significado mental, um conteúdo inteligível. O ícone e a palavra escrita remetem para a verbal, mesmo quando a pronunciamos mentalmente. Os demais códigos devem ser traduzidos das suas regras de combinação e reduzidos às regras de comunicação verbal. São parasitários em relação à linguagem escrita, e esta é parasitária em relação à linguagem verbal.Também as imagens dos percepta devem ser traduzidas. Damos-lhes, ou não, um sentido.

\section{ANÁLISE}

Na preparação da análise a que procedi até agora, utilizei os instrumentos e os conceitos da semiologia, mas não fiz semianálise. A semiologia não está voltada para as ligações do signo com o seu eventual referente objetivo, mas para a constituição interna do signo, para o seu poder significante, e, por isso, para as relações significante-significado (ECO, 1977, p. 115). A utilização da semiologia estruturalista como ferramenta de análise, por seu turno, na forma que faço aqui, volta-se para a discussão do sistema sígnico enquanto denotativo de algo latente. Isto é, para a interpretação dos valores que se encontram por trás do referente, para o desvelamento da intenção por trás do signo, para o encontro do sentido da expressão por trás da representação.

O escopo da análise estrutural não é a verdade da mídia, mas o seu plural. Não se trata de partir do texto, das formas, dos signos, para perceber, esclarecer ou formular conteúdos, mas, ao contrário, trata-se de dissipar, fazer aparecer os primeiros conteúdos sob a ação de uma ciência formal (BARTHES, 2004, p. 186). Começamos com os códigos familiares. Depois os abandonamos em favor dos significados desvelados. A análise estrutural nos leva a uma hermenêutica (interpretamos os signos e os seus valores simbólicos), tanto como a uma heurística (descobrimos significados). Dessa hermenêutica e dessa heurística construírmos estruturas; damos uma lógica, um sentido, dentre outros possíveis, àquilo que lemos, que vemos, que analisamos.

\section{Interpretação}

O conjunto de convenções sociais que governam as escolhas e o alcance das expressões com significação está baseado em oposições subjacentes que determinam os valores embutidos no sistema. Mesmo quando os indivíduos da mesma coletividade intra-organizacional não compartilham inteiramente uma metalinguagem, existem zonas de superposição: serviços ou indivíduos que servem de pontes, de tradutores. Mas, se queremos alcançar descrever a estrutura subjacente à intranet para além da tradução, realizada por quem nela navega, devemos proceder a uma interpretação. A tradução transpõe o signo de um código para outro, a interpretação determina o sentido do signo em um domínio.

$\mathrm{Na}$ pesquisa estruturalista descrevemos o objeto a partir de um, e somente de um, ponto de vista (BARTHES, 1971, p. 103). Da massa heterogênea dos fatos retemos os traços pertinentes a este, e 
só a este ponto de vista, com exclusão de todos os outros. A semiologia estruturalista estuda o sentido dos objetos; a sociologia, as relações entre pessoas e grupos; a ciência política, as relações de poder, e assim por diante. Os outros determinantes não são abandonados, mas tratados em termos do ponto de vista adotado. $\mathrm{Na}$ interpretação que se segue considerei os elementos econômicos, políticos, sociológicos, em termos do ponto de vista da ideologia que anima os instrumentos de gestão, da forma que assumem as organizações e da maneira como são administradas.

\section{Fontes}

As fontes que utilizei para a análise e interpretação são múltiplas. Até que a amostra saturasse, foram consideradas 22 (vinte e duas) intranets empresariais e de organismos governamentais e 6 (seis) sistemas de construção de intranet. Das intranet consideradas, 18 se encontram na internet ou são citadas em seminários, conferencias e congressos divulgados via internet. Os prazos, as exigências autorais e as ressalvas impostas pelos proprietários desses sistemas tornaram proibitivas as citações das fontes. Referências, aliás, inteiramente dispensáveis, dado o método de saturação utilizado na análise. A seguir consta um quadro referencial dos elementos

\section{QUADRO 1}

\section{Elementos e significantes com frequências de ocorrência}

\begin{tabular}{|c|c|c|c|}
\hline Elemento & Significante & & $(\%)$ \\
\hline o desktop, portal, home & casa & & 100 \\
\hline posto de trabalho virtual, (e-office ou e buro); & & & 34 \\
\hline boletim de notícias (event calendar); & jornal & & 58 \\
\hline ferramenta de busca & binóculo / lente & & 95 \\
\hline diretório & & & 94 \\
\hline endereços & lista & 32 & \multirow{2}{*}{100} \\
\hline contatos & lista & 68 & \\
\hline correio & envelope & & 100 \\
\hline formulários de gestão de RH & formulário & & 73 \\
\hline o organizador de tarefas & livro aberto & & 83 \\
\hline bloco de notas & livro aberto & & 94 \\
\hline "sub-sites" (chat rooms, e-rooms, comment trails) & pessoas & & 29 \\
\hline lixeira & cesta & & 100 \\
\hline
\end{tabular}

e significantes com as respectivas frequências de ocorrência entre os 28 sistemas utilizados (quadro 1).

\section{Corpus}

A primeira aproximação ao domínio circunscrito pela intranet se dá pelo / portal/, pela página do / menu/. Nele, a apresentação dos signos é espacial. O código tem uma mensagem única: "eis aqui as informações que estão disponíveis". Cada signo é um interpretante: remete para outros signos. A análise da cadeia de significação de cada signo nos transporta de uma estrutura superficial, em que os elementos - termos, ícones, indícios - são manifestos, e que constitui a parte visível da intranet, a tela, para uma estrutura profunda, a estrutura da ideologia de gestão.

O estudo estruturalista é imanente e determinado. Nele, o sistema é observado desde o seu interior. O conjunto de elementos pertinentes à pesquisa, os fatos, dados, informações, constitui um corpus - uma coleção finita de objetos, determinada de antemão (BARTHES, 1971, p. 104). O corpus desta análise é formado pelos signos recorrentes nas intranets (cf. o item "Fontes", adiante): o desktop, portal, bome ou página principal, onde se encontram as boasvindas, o sistema de identificação e autorização e, 
principalmente, a chave hipermídia de acesso às informações e ferramentas disponíveis, a saber:

- um conjunto de funções que constitui o posto de trabalho virtual: (e-office on e bureau);

- um /boletim de notícias/ de interesse intraorganizacional (event calendar);

- uma / ferramenta de busca/ do site, geralmente representada por uma lente ou por um binóculo;

- o / diretório/ de opções, que, em geral, figura em uma tela à parte;

- a ferramenta de armazenagem e disponibilidade de /endereços/;

- a de /contatos/;

- uma ferramenta de / correio/ (recepção, armazenagem e envio de mensagens), geralmente representada por um envelope;

- uma série de /formulários/ de gestão de RH, notadamente informações e inscrições do sistema de capacitação funcional (e-learning);

- o /organizador/ de tarefas, ao qual geralmente vai associado um / calendário/ móvel;

- um /bloco de notas/, geralmente representado por um caderno ou por uma folha de papel;

- "sub-sites" de compartilhamento de informações e de documentos (chat rooms, e-rooms, comment trails)

- uma/lixeira/, onde são armazenados temporariamente os itens descartados, simbolizada por uma cesta.

\section{Escolha e assentimento}

Entramos no ambiente intranet a convite. Em tese, podemos não fazê-lo. Podemos não utilizar a intranet. Mas esta alternativa é puramente teórica. Quem não frequenta os seus meandros, quem não usa os seus aplicativos, afasta-se das oportunidades e da vida intraorganizacional. É pré-excluído do sistema de informações e de relações intersubjetivas da organização.

Ci. Inf., Brasília, v. 38, n. 2, p. 110-125, maio/ago. 2009
A entrada na intranet se dá pela tela denominada "lar" (bome), desktop, / página principal/ ou, mais frequentemente, /portal/. O seu signo é uma casinha estilizada. Do / portal/ é de onde partimos e para onde voltamos quando terminamos nossas tarefas ou quando não sabemos (mais) aonde ir. É o lugar de abrigo e de escape. Podemos voltar ao / portal/ a qualquer momento e de qualquer lugar. Ele é único, não se subdivide em opções. É a porta de um mundo limitado, mas que se faz de infinito. Ou que é infinito como a circunferência é infinita: uma infinitude que sempre nos leva ao mesmo ponto.

A ilusão da escolha e a impressão de infinitude estão intimamente associadas. Mas nem as opções são infinitas, nem a escolha é real. $\mathrm{Na}$ intranet, não escolhemos entre alternativas (ir ou não ir para a tela de tarefas, por exemplo). Apenas assentimos. Aquiescemos em seguir os caminhos já demarcados. Nós não os demarcamos. Não somos nem o pioneiro nem o guia, mas os seguidores. Somos os que assentem em comum, os que consentem em seguir as rotas traçadas, em selecionar as alternativas préprogramadas dos menus. Faltam-nos os elementos de uma escolha verdadeira. Não temos escolha, ou melhor, nós só temos uma escolha: ficar ou partir. Ao ficar, assentimos, aceitamos as regras do jogo do sistema.

\section{Amplitude e estreitamento}

Entramos no ambiente intranet e nos vemos em um mundo restrito. O / diretório/ (directory), os /contatos/ (contacts), /endereços/ (address) são ordenados, numerados, circunscritos. Eles nos dizem qual o mundo disponível; até onde podemos ir, na diversidade limitada. Indicam quem são os outros. Revelam o seu signo o seu / nome de uso/ (username; user-id); não o nome verdadeiro, mas o utilizável. Aquele que pode ser abordado, ou que não pode, porque está sempre distante, mas que sabemos onde está ou onde deveria estar. Os / contatos/ são a ponte para os outros legitimados. Não para os outros em geral, mas para os outros autorizados, os que são alguém, os destinatários a quem poderemos enviar uma mensagem, os que 
significam. Contatamos os (re) conhecidos por nós e, em ultima instância, pelo sistema.

$\mathrm{Na}$ intranet, o tempo, a terceira dimensão também se encontra circunscrita. As / tarefas/ (tasks) listam os compromissos, os atos que obrigamo-nos a fazer. A todo o momento / adicionamos/ ( $a d d$ ) obrigações à nossa vida futura. Enviamo-nos mensagens para serem lembradas no tempo que está por vir, no qual a / tarefa incompleta/ (inconplet task) nos espreita com seu olhar zeloso. $\mathrm{Na}$ autovigilância que nos restringe (vigiar já é punir; veja-se Foucault), não há prêmio pelo que fizermos, somente a indicação do quanto fizemos (status), do momento em que deveríamos ter começado e terminado a tarefa, da repreensão moral exposta pela lembrança do que deixamos de fazer. O / calendário/ (calendar) está sempre associado às/tarefas/, aos afazeres (to-do list). Fracionamos ou englobamos o futuro em semanas, meses, anos. Iludimo-nos com a ideia de que, por meio do sistema, podemos controlar o futuro. A profecia sobre o nosso destino, registrada nas/tarefas/, nos/lembretes/, nas /notas/ e nos signos correspondentes da moldura, do bloco de papel amarelo, do caderno aberto, atesta o nosso compromisso. Nosso destino (com)sagrado.

$\mathrm{Na}$ intranet, a jaula de ferro, a iron cage, de Max Weber (1950) foi trocada pela jaula eletrônica. Digitalizouse a racionalidade formal-instrumental do estado, da economia, das organizações e das decisões privadas, que vai desembocar no "espírito coagulado" do capitalismo monetarizado, da vida juridificada em que estamos contidos e nessa "escura noite polar" quantitativizada que a humanidade atravessa (SCAFF, 1989, p. 85). O que nos é oferecido como alternativa à predeterminação, o que se apresenta superficialmente como escolha livre, na verdade é um esquema fechado de assentimento. Consentimos em estreitar nossas perspectivas, em arrolar nome e endereço das pessoas e instituições com as quais nos relacionamos, em divulgar nossas tarefas, em prever nosso futuro, em alienar nosso pequeno mundo a um mundo virtual, asséptico, circunscrito, controlado, mas não por nós.

\section{Inclusão e subordinação}

A única escolha efetiva que a intranet nos oferece é a da inclusão, a da possibilidade de não sermos excluídos, de estarmos (por) dentro da organização. Mas nos cobra um preço: o da subordinação. Os traços, pontos e estrelas que piscam, tremeluzem e oscilam são o significante da incompletude das tarefas, das decisões a tomar, das molduras vazias. Somos convidados insistentemente a fazer, a completar, a preencher, a ir. Jamais nos desobrigarmos de compromissos. É um ciclo sem fim, engendrado para (nos) informar onde estamos, o que fazemos, o que faremos. Destinado a prestarmos vassalagem ao sistema.

A relação que une o significado ao sentido no código intranet é, essencialmente, uma relação de subordinação. O significado original do signo é perdido. O signo é privado do seu sentido (a seta à esquerda, por exemplo, não nos faz ir para a esquerda, mas voltar para onde estávamos anteriormente). Ao entrar no sistema, obrigamo-nos a seguir suas regras. Transitamos ("navegamos", embora não haja nada mais seco do que uma tela de computador nem mais imóvel do que um usuário) segundo um cânone, uma regra arbitrária, estabelecida em um tempo anterior e exterior a nós e à nossa cultura. A tela da intranet é um discurso definido pela sua intenção não manifesta. Ou nos subordinamos ao sistema, ou não podemos navegar; ou apreendemos o paradigma, ou somos excluídos. Por trás do código, do signo e do sentido que assimilamos, há uma ideia-força, uma ideologia, uma dominação. Ao navegar pela intranet não somos guiados propriamente. Ninguém vai à nossa frente; somos pastoreados, como carneiros.

$\mathrm{Na}$ aparência, os caminhos que seguimos são claros e desimpedidos. Mas só na aparência. A tela não esconde nem revela nada diretamente. Os seus interpretantes conduzem, nos conformam a uma ordem. A significação apreendida é que integramos a organização, que a organização nos abraça, ensina e protege. De que nós, os autorizados a navegar na intranet, somos a organização. Mas a verdade é que nós, os trabalhadores, não somos a organização, nós

Ci. Inf., Brasília, v. 38, n. 2, p. 110-125, maio/ago. 2009 
só estamos na organização, não constituímos sua essência; somos dispensáveis. Só circunstancialmente nós a integramos, e, se ela nos abraça, o faz por interesse, como no amor a frete. Se a intranet nos informa e nos abriga da falsa informação, do boato, do mexerico, ela não nos protege contra ela mesma e contra os interesses organizacionais. A mensagem por trás da neutralidade das telas não é a de que nós somos a organização: a mensagem a ser internalizada é a de que sem ela nós nada somos.

A inclusão é um enantiossema (BARTHES, 2003, p. 58), ela tem dois contrários. A exclusão é o mais evidente. O outro é a inclusão condicional, incompleta: a subordinação. Somos incluídos na intranet desde que, dependendo de, sob a condição de sermos membros da organização, de seguirmos suas regras, de figurarmos em sua estrutura. Perante a pseudoneutralidade do sistema, obrigamo-nos a ir, a completar, a fazer, a preencher. Nós relacionamos com o mundo, com a organização, com os outros e conosco mesmos através e segundo um modelo anterior e exterior a nós e à nossa vontade. (Nos) perguntamos e (nos) respondemos. Somos as sentinelas e os prisioneiros do sistema que alimentamos. Somos um dos elementos predefinidos da estrutura; ajustados e descartáveis.

\section{Participação e reclusão}

Sem outra escolha além da exclusão da vida organizacional, assentimos em entrar no mundo na intranet. Ao nos subordinamos ao código paradigmático da intranet, ingressamos em um mundo segregado. O que nos é oferecido como alternativa aos sistemas autoritários, que sonegam informações, é, em verdade, um sistema de reclusão. Sob pena de sermos excluídos do sistema de comunicação intraorganizacional, tornamo-nos prisioneiros deste sistema.

O portal da intranet se abre para um espaço fechado. É como um jardim em que somente algumas alamedas são franqueadas ao visitante. Ao percorrêlas, reconstruímos caminhos como montamos um quebra-cabeça: cada imagem, cada representação, cada opção que escolhemos tem um lugar prédemarcado. Ao assinalarmos as alternativas dos pоp-up e dos pop-down, respondemos a perguntas que já vêm prontas. Optamos entre respostas já dadas. Tiramos nossas dúvidas por mail ou por telefone, desde, claro está, que sejam dúvidas operacionais. Há só uma forma correta de duvidar, de responder, de perguntar. $\mathrm{O}$ artifício eletrônico elude, mas não elimina a canônica do dubitativo, do responsório, da inquisição.

Os sistemas de colaboração (chat rooms, comment trails) são antes de tudo sistemas de controle. São administradores das / tarefas/ em comum (task management systems), são proclamadores de deveres. Oferecem / notícias/ de interesse imediato (bulletin boards), de interesse operacional (e-plans), ou que só interessam ao diversionismo que bloqueia a reflexão autônoma e os sentimentos individuais que estimulam a produção (news letters). Agilizam a burocracia intraorganizacional (formulários de RH), mas não a nossa vida funcional: custa-nos tanto esforço e tempo preencher os formulários e questionários eletrônicos como os de papel. O compartilhamento da informação, as contribuições para o aperfeiçoamento administrativo (caixas de sugestões), os mini-sites (e-rooms) agregam valor sem contrapartida, cortam custos e incrementam receitas sem que o esforço imaginativo e o esforço produtivo do trabalhador sejam remunerados. A forma digitalizada agiliza tanto a produção como a expropriação do sobretrabalho.

A hipermídia da intranet é topológica. Ela diz que estamos aqui e que podemos ir (até) lá, desde que passemos por ali e que não ultrapassemos a informação consentida. Para além dos dados e informações operacionais, ela remete a outras estruturas: de poder, de relações pessoais, de edificações, de máquinas e equipamentos, de finanças, dos objetivos tangíveis e intangíveis da organização; de conhecimentos e saberes. Mas ela vela, ela filtra a intimidade da organização. Ela dissimula o que não deve ser proclamado. Ela mostra a excelência, o mérito, a força; mas ela esconde a lacuna, a nódoa, o defeito, a exploração. 
A intranet é um portal de dupla tranca. Fechado aos não iniciados, aos não membros, e fechado aos inconformados, aos inadaptados, aos reformadores, é tanto uma vitrina quanto um cárcere. A tela da intranet é lida como uma fonte de informações, mas ela é um sistema de reclusão. O usuário da intranet navega por canais, não pelo mar aberto; é um consumidor da informação consentida. É um concessionário, não um proprietário do seu próprio trabalho.

\section{Persuasão e segregação}

Compulsória, fechada sobre si mesma, soberana, restritiva, a intranet é antes uma estrutura de segregação do que um sistema de informação. A figura principal do segregacionismo informacional da intranet é a persuasão, fundada na camuflagem - que consiste em oferecer como escolha o que na realidade é um compromisso - e fundada na retificação (BARTHES, 1978, p. 173) - que consiste em reduzir a qualidade à quantidade, o definitivo ao provisório, o intelecto à racionalidade instrumental.

A camuflagem está na polissemia (o múltiplo do sentido) (BARTHES, 2003, p. 87). O signo e o código fazem com que as mensagens do sistema intranet assumam uma forma equívoca. O binóculo faz com que o sistema seja tido como transparente, a lente como grandioso, as bordas como completo. O conjunto de ícones de aparatos antiquados e familiares (lentes, binóculos, cadernos, ampulheta, etc.), induzem a pensar que o sistema é amigável. Mas ele não é nada disto: ele é opaco, tacanho, impessoal, parcial, autoritário. Os signos da intranet são estilizações (de-formidades) que operam mais no nível do estímulo (busque!; escreva!; aguarde!) do que como sinais de uma linguagem. São imagens empobrecidas: o binóculo perde o regulador e a correia, a lente perde parte da empunhadura, a palavra é abreviada, o verbo vem no infinitivo. São signos libertos da circunscrição de um código único; têm valor semântico (remetem para um significado) e não, ou pelo menos não principalmente, valor sintático (ECO, 1977, p. 62). Servem para ordenar, não para conversar. Estão na ordem da interjeição, não da do diálogo.

A retificação está no próprio paradigma. A maioria dos signos da intranet exprime somente a sua relação recíproca: "clique aquil, "vá para a tela de tarefas". "escreva aqui", etc. A contabilização do número de visitas à tela principal ou o valor emprestado ao número de contatos reduz a qualidade à quantidade, o concreto ao efêmero. $\mathrm{Na}$ intranet, nada é definitivo. Até mesmo o que desprezamos vai para uma lixeira, para um depósito, uma espécie de purgatório, um lugar temporário, até que resolvamos eliminá-lo de vez. Mas a destruição da informação é controlada. O sistema reage a qualquer ameaça de descarte com uma contrainformação: com perplexidade: "tem certeza de que quer apagar estes dados", e com indignação: "estes dados serão definitivamente perdidos!" Procura iludir o efêmero e volátil, com a ilusão do permanente e do sólido.

Os significantes da intranet são dúbios, indecisos. O envelope semiaberto (o significante de /correio/), tal como a pasta semiaberta (o significante de /pasta de documentos/ e de /conjunto de subpastas/), o caderno (o significante de /livro de anotações/), apenas se entreabrem. Estão semifechados antes do que semiabertos. Os seus conteúdos são conteúdos de determinada espécie. Devem ser operacionais, frios, porque eles se abrem para a curiosidade alheia e para a vistoria da organizaçãoproprietária da intranet. A sua permeabilidade é seletiva: oferecem-se somente para alguns e para determinadas informações. São signos definitivos de um sistema em que ingressamos para sermos confinados, vigiados, dirigidos.

O traço vertical que pisca no início do boxe (moldura) vazio é um signo universal, mas não tem um conteúdo, uma mensagem de interesse não operacional. Ele indica, ele incita (escreva!), mas não informa. É um estímulo, um indício, como a moldura vazia em baixo relevo, a palavra circunscrita em negrito, o triângulo que aponta para baixo. São ordenadores: vá!; aqui! Não levam até à informação, nem, diretamente, ao lugar em que 
se pode encontrá-la, mas ao lugar em que se deve procurá-la. São indutores, servem para persuadir que o uso da tecnologia da informação nos transporta para um plano mais alto de decisão.

A intranet demarca o limite informacional interno da organização e determina a sua estrutura comunicacional. As fronteiras da organização são delimitadas pelo controle autônomo exercido sobre recursos - patrimoniais, financeiros, informacionais e humanos - e os sobre processos. A estrutura superficial da intranet é comunicativa e aberta. A estrutura profunda ancora um sistema de controle e restrição. A ponte que une as duas estruturas, o código dinâmico (BARTHES, 2004, p. 186) é a da camuflagem e o da retificação. Sob a superfície ilusória da escolha, da inclusão e da participação, a intranet dissimula o assentimento, a subordinação e a reclusão. Sob a máscara da integração comunicacional, a intranet encobre uma estrutura de segregação.

A análise estrutural da intranet mostra que ela ilude. Ela esconde que a coabitação com a alta tecnologia não implica necessariamente a democratização da comunicação organizacional e que a democratização da informação não reside unicamente no direito irrestrito de acesso, mas também e principalmente no direito à expressão das ideias e valores individuais. Na intranet, a dúvida pré-programada nos é oferecida em troca da incerteza criativa do intelecto, a razão é reduzida à racionalidade, a informação é policiada, a comunicação é contida dentro dos limites da conveniência de quem institui o sistema.

Artigo submetido em 05/12/2008 e aceito em 23/07/2009.

\section{REFERÊNCIAS}

AQUINAS, Saint Thomas. The summa theologica. Chicago: Enciclopædia Britannica, Inc., 1975.

BACHELARD, Gaston. O direito de sonhar. São Paulo: Difel, 1985.

BARLEY, Stephen R. Semiotics and the study of occupational and organizational cultures. Administrative Science Quarterly, v. 28, p. 393413, Sept. 1983.

BARTHES, Roland. Elementos de semiologia. São Paulo: Cultrix, 1971. Mitologias. Rio de Janeiro: Difel, 1978

O grau zero da escrita, seguido de novos ensaios críticos. São Paulo: Martins Fontes, 2004.

Roland Barthes por Roland Barthes. São Paulo: Estação Liberdade, 2003.

BOURDIEU, Pierre; PASSERON, Jean-Claude. A reprodução: elementos para uma teoria do sistema de ensino. Rio de Janeiro: Francisco Alves, 1982.

ECO, Umberto. O signo. Lisboa: Editorial Presença, 1977.

FOUCAULT, Michel. Vigiar e punir. Petrópolis: Vozes, 1977.

GLASER, B.; STRAUSS, A. The discovery of grounded theory: strategies for qualitative research. Chicago: Aldine, 1996.

JARDIN, Evelyne. Quand les organisations communiquent. Sciences Humaines, v. 36, p. 50-54, mar./maio 2002.

MARTY. Robert. La dimension perdue de Roland Barthes. Disponível em: $<$ http://www.come.to/robert.marty>.

MORSE, Janice M. The significance of saturation. Qualitative Health Research, v. 5, n. 2, p. 147-149, 1995.

PARAIN-VIAL, Jeanne. Análisis estructurales e ideologias estructuralistas. Buenos Aires: Amorrurtu Editores, 1972.

PIAGET, Jean. O estruturalismo. Rio de Janeiro: Difel, 2003.

PIRÈS, A. P. Échantillonnage et recherche qualitative: essai théorique et méthodologique. In: POUPART, J. et al. (Ed.). La recherche qualitative: enjeux épistémologiques et méthodologiques. Montréal: Gaëtan Morin, 1997. p. 113-169.

RICOEUR, Paul. De l'interprétation: essai sur Freud. Paris: Editions du Seuil, 1965.

RUSS, Jacqueline. Les méthodes en philosophie. Paris: Armand Colin, 1996.

SCAFF, Lawrence A. Fleeing the iron cage. Berkley: University of California Press, 1989.

WEBER, Max. The protestant ethic and the spirit of capitalism. New York: Charles Scribner's Sons, 1950. 